\title{
Morpho-molecular Identification and Chemical control of Alternaria alternata,causing leaf blight of Gardenia jasminoides Eills in China
}

\section{Anna Zhao}

Jiangxi University of Traditional Chinese Medicine

\section{Yuhong Gong}

Jiangxi University of Traditional Chinese Medicine

Guangming Luo

Jiangxi University of Traditional Chinese Medicine

Yangjin Luo ( $\square$ lyj_20080819@126.com )

Jiangxi University of Traditional Chinese Medicine

Dandan Song

Jiangxi University of Traditional Chinese Medicine

Hongdong Xia

Jiangxi University of Traditional Chinese Medicine

\section{Research Article}

Keywords: leaf blight, Alternaria alternata, chemical control

Posted Date: November 1st, 2021

DOI: https://doi.org/10.21203/rs.3.rs-961196/v1

License: () (1) This work is licensed under a Creative Commons Attribution 4.0 International License.

Read Full License 


\section{Morpho-molecular Identification and Chemical control of Alternaria alternata,causing leaf blight of Gardenia jasminoides Eills in China}

Anna Zhao ${ }^{1} \cdot$ Yuhong Gong ${ }^{1} \cdot$ Guangming Luo*1 $\bullet$ Yangjin Luo*1 $\bullet$ Dandan Song ${ }^{1} \bullet$ Hongdong Xia ${ }^{1}$

$\triangle$ Guangming Luo: jzlgm88@,163.com

$\triangle$ Yangjin Luo: 1yj_20080819@126.com

${ }^{1}$ College of Pharmacy, Jiangxi University of Traditional Chinese Medicine, Nanchang 330000, Jiangxi, China

Abstract Gardenia jasminoides Eills is a traditional aromatic and medicinal plant that is widely cultivated in China. In 2020, a severe leaf disease on Gardenia was observed in a growing herbal medicine area in Jian County, of Jiangxi Province, China. The causal agent was identified as Alternaria alternata (Fr.) Keissler. by amplification and sequencing the internal transcribed spacer (ITS) region, followed by phylogenetic analysis. Koch's postulates were confirmed by a pathogenicity test conducted with healthy gardenia, including reisolation and identification. To our knowledge, this is the first report of leaf blight caused by Alternaria alternata on Gardenia jasminoides Eills in JiangXi, China. PDA plate bacteriostatic experiment results showed that: Hexaconazole had the best inhibiting effect, which the $\mathrm{EC}_{50}$ was $14.45 \mathrm{ppm}$. Therefore, the 
results are preliminary but promising for future field applications.

Keywords leaf blight• Alternaria alternata $\cdot$ chemical control

\section{Introduction}

Gardenia jasminoides Eills, belonging to the family Rubiaceae, is a famous ornamental plant widely distributed worldwide. The central officinal part of $G$. jasminoides is its dried ripe fruit. Chemical composition analysis finds multiple secondary metabolites in the fruit of G. jasminoides, like iridoid glycosides, crocin and crocetin, which have broad-spectrum anti-inflammatory properties, anti-cancer effects even can treat cerebral diseases (Zhang et al. 2021). The crocus sativus glycoside in gardenia fruit can still be used to produce gardenia red, gardenia yellow, gardenia blue, three kinds of pigment, as a natural colourant widely used in the food industry (Wu et al. 2021). There is a great demand for gardenia in China due to its wide application in the medicine and food industry. As wild gardenia was not enough to meet the demand of many people, people began to cultivate gardenia on a large scale to produce more gardenia for people to use. However, the large-scale planting of gardenia resulted in the decline of disease resistance and the frequent occurrence of disease, which seriously affected the yield and quality of gardenia.

Leaf blight is a common disease in rice (Oryza sativa L.), wheat (Triticum aestivum L.), apple (Malus pumila Mill.), maize (Zea mays L.) (Mehl et al. 
2021), garlic (Allium sativum L.) (Gálvez et al. 2016) and other plants. Once it happens, it is easy to break out and become a disaster, which seriously affects the growth and yield of plants and causes great economic losses. This is the first time that the leaf blight was observed in the gardenia planting base in Jiangxi province. The disease begins to infect the leaf margin, with irregular spots and later a large area of dry up, leading to plant death in severe cases. At present, the task is to identify the pathogen causing leaf blight and search for drugs to control the disease.

\section{Materials and methods}

\section{Isolates Used and Morphologica I Observation}

Survey of herbal medicine growing areas in Jian country $\left(114^{\circ} 09^{\prime} \mathrm{E} 27^{\circ}\right.$ $07^{\prime} \mathrm{N}$ ) was carried out to assess the prevalence of the disease. The fungi from the infected samples were isolated using routine tissue isolation method. Leaves were disinfected with $0.5 \% \mathrm{NaClO}$ for 5 min and washed twice with sterile distilled water. Small pieces from the edges of diseased tissue were placed on potato dextrose agar (PDA) medium. The isolated pathogens were purified using hyphal tip technique. After culturing for two days at $30^{\circ} \mathrm{C}$, transferred to a new PDA plate followed by incubation at $30^{\circ} \mathrm{C}$ for five days. Emerging colonies were transferred several times by the hyphal tipmethod until and pure cultures were obtained. After five days, the morphological features of the culture of each isolate were 
studied on PDA at $30{ }^{\circ} \mathrm{C}$. The sterile cultures were stored at $4{ }^{\circ} \mathrm{C}$ in a refrigerator.

\section{Pathogenicity test}

The purified fungi were inoculated on healthy leaves and cultured in darkness in a constant temperature incubator at $30{ }^{\circ} \mathrm{C}$, with control leaves instead of being inoculated using fungi-free PDA. After 48 hours, the incidence was observed, recorded the symptoms and characteristics of the injury were and took photos were for preservation. To complete Koch's postulates, fungi were isolated from diseased parts of inoculated Leaves, using the same method as when pathogenic bacteria were isolated. The morphological characteristics of the isolated microorganisms were observed and recorded.

\section{Molecular identification}

Mycelium was used to extract the genomic DNA by following the CTAB method described by Möller et al. primers ITS1 and ITS4 were used to amplify the ITS region of DNA. The polymerase chain reaction (PCR) was performed in an iCycler Thermal Cycler in a final volume of $50 \mu \mathrm{L}$ containing $25 \mu \mathrm{L}$ of $2 \times \mathrm{PCR}$ mix, $2 \mu \mathrm{L}$ of each primer $(10 \mu \mathrm{M}), 2 \mu \mathrm{L}$ of DNA (10 ng), and $19 \mu \mathrm{L}$ of double-distilled H2O. The PCR conditions include the 4 min duration for the initial denaturation at $95^{\circ} \mathrm{C}$; followed by 35 cycles of $60 \mathrm{~s}$ at $94^{\circ} \mathrm{C}, 60 \mathrm{~s}$ at $54^{\circ} \mathrm{C}$, and $60 \mathrm{~s}$ at $72^{\circ} \mathrm{C}$; and a final extension of $10 \mathrm{~min}$ at $72^{\circ} \mathrm{C}$. The resulting PCR products were analyzed 
by gel electrophoresis in a $1 \%$ agarose gel in $1 \times$ Tris-borate-EDTA buffer and sequenced by Sangon Biotech Co., Ltd. (Shanghai, China). The amplified sequence was compared with the other sequences found in the National Center for Biotechnological Information (NCBI) database using the Basic Local Alignment Search Tool (BLAST). The MEGA-X (Molecular Evolutionary Genomics Analysis Version-X) constructed dendrograms from the isolates from the current study and reference strain sequences from GenBank. There were 100 replications for every bootstrap value. The pathogenic bacteria species were finally determined with the results of morphological observation, microscopic identification, and determination of pathogenic bacteria pathogenicity.

\section{In vitro fungicide testing}

Fifteen commercial chemical fungicides were considered. Before putting PDA into Petri dishes, fungicides were added in five different concentrations of the active ingredients: $10,30,50,70,100 \mathrm{ppm}$. Fungicide and active components (ai) are listed in Table 1.

At the end of the trials, the percentage of mycelial growth reduction (GR\%) was calculated using theformula: GR $\%=R C-R A / R C \times 100 \%$

$\mathrm{RC}$ : colony radius $(\mathrm{mm})$ of the control strain.

RA: colony radius $(\mathrm{mm})$ of the strain indual culture with the pesticides in amended PDA.

Table.1 Fungicides and biocontrol agents used for in vitro testing

COMMERCIAL PRODUCT ACTIVE INGREDIENT COMPANY




\section{Chemicals}

\begin{tabular}{|c|c|c|}
\hline Hexaconazole & hexaconazole & $\begin{array}{c}\text { Guangdong Zhongxun Agricultural Science Co., } \\
\text { Ltd, CHINA }\end{array}$ \\
\hline Xin Jun Ma Lin Gua & $\begin{array}{l}\text { Moroxydine hydrochloride } \\
\text { Octreotide acetate }\end{array}$ & $\begin{array}{l}\text { Qingdao Runtian Biotechnology Co., Ltd, } \\
\text { CHINA }\end{array}$ \\
\hline Tricyclazole & Tricyclazole & $\begin{array}{l}\text { Guangdong Zhongxun Agricultural Science Co., } \\
\text { CHINA }\end{array}$ \\
\hline Jia Ji Liu Junling & Thiophanate-Methyl & $\begin{array}{l}\text { Guangdong Zhongxun Agricultural Science Co., } \\
\text { Ltd, CHINA }\end{array}$ \\
\hline 5-Xiao Duojunling & $\begin{array}{c}\text { Carbendazim } \\
\text { Pentachloronitrobenzene }\end{array}$ & $\begin{array}{l}\text { Guangdong Zhongxun Agricultural Science Co., } \\
\text { Ltd, CHINA }\end{array}$ \\
\hline Bai Junqing & Chlorothalonil & $\begin{array}{l}\text { Bannong Sida (Beijing) Agro-Chemicals Co., } \\
\text { Ltd, CHINA }\end{array}$ \\
\hline Duo Junling & carbendazim & Shanghai Yilian Chemical Co., Ltd , CHINA \\
\hline Dai Sengxin & Dithane $z^{-78}$ & $\begin{array}{l}\text { Qingdao Runtian Biotechnology Co., Ltd, } \\
\text { CHINA }\end{array}$ \\
\hline Jia Ji Tuo Bu Jing & Thiophanate-Methyl & $\begin{array}{l}\text { Qingdao Runtian Biotechnology Co., Ltd, } \\
\text { CHINA }\end{array}$ \\
\hline Fu Meishuang & thiram & $\begin{array}{l}\text { Beijing Green Agricultural Science and } \\
\text { Technology Goup Co., Ltd, CHINA }\end{array}$ \\
\hline \multicolumn{3}{|l|}{ Biological } \\
\hline 01igosaccharins & oligosaccharins & $\begin{array}{l}\text { Beijing Green Agricultural Science and } \\
\text { Technology Goup Co., Ltd, CHINA }\end{array}$ \\
\hline Streptomycin & streptomycin & $\begin{array}{l}\text { Qingdao Runtian Biotechnology Co., Ltd, } \\
\text { CHINA }\end{array}$ \\
\hline $\begin{array}{l}\text { Streptomycin } \\
\text { sulfate }\end{array}$ & $\begin{array}{l}\text { Streptomycin } \\
\text { sulfate }\end{array}$ & $\begin{array}{l}\text { Beijing Boaotuo Technology Goup Co., Ltd, } \\
\text { CHINA }\end{array}$ \\
\hline Oxytetracycline & 0xytetracycline & $\begin{array}{c}\text { Beijing Boaotuo Technology Goup Co., Ltd, } \\
\text { CHINA }\end{array}$ \\
\hline $\begin{array}{l}\text { Gentamycin } \\
\text { sulfate }\end{array}$ & Gentamycin sulfate & $\begin{array}{l}\text { Beijing Boaotuo Technology Goup Co., Ltd, } \\
\text { CHINA }\end{array}$ \\
\hline
\end{tabular}

\section{Results}

Multiple fungal strains were isolated and purified from gardenia leaf blight collected in the field. The pathogenicity was determined according 
to Koch's rule, and one of them was determined to be the pathogen of the disease, which was temporarily named GD1.

\section{Morphological characterization and identification}

Morphological characteristics of the causal pathogens were studied both on the host and artificial culture medium to identify the associated pathogen, which was studied on the PDA medium. The pure culture of the GD1 initially produced white colonies (Fig. 1A), which gradually turned to light brown in 2 days and attained a growth of $9 \mathrm{~cm}$ in 7 days. Microscopic observations revealed that the hyphae are smooth and septate, the conidia are chain, the base is blunt and round, the other end is pointed, and there are vertical and horizontal septa. Generally, there are 1-3 transverse septa, 1-6 mediastinum, the spore size is $9.9-35.2 \mu \mathrm{m}$ $\times 5.9-12.5 \mu \mathrm{m}$, the average size is $18.8 \mu \mathrm{m} \times 7.9 \mu \mathrm{m}$ (Fig. 1B).

These characteristics are consistent with the morphological characteristics of Alternaria alternata (Fr.) Keissler. 

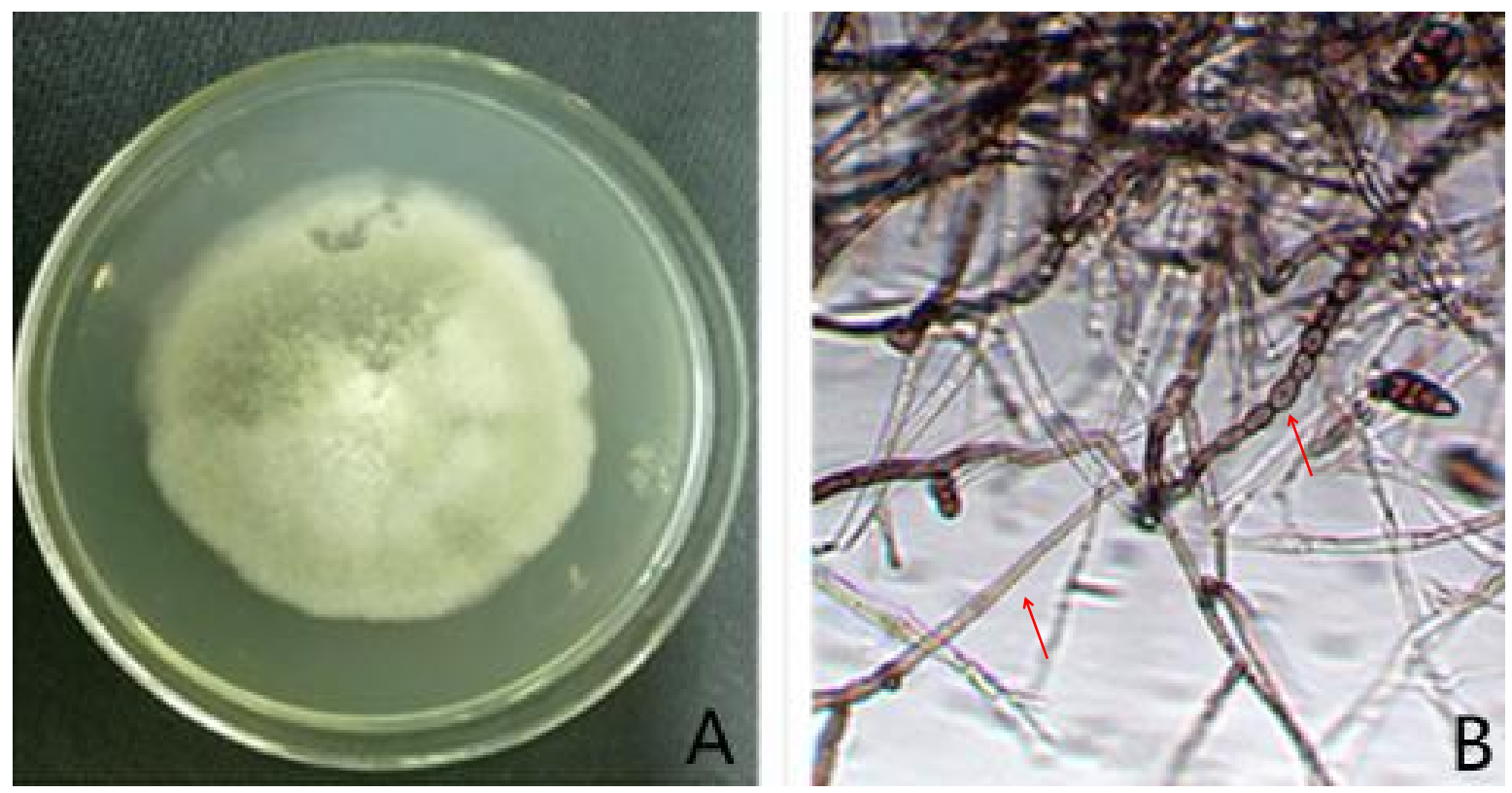

Fig1. Morpho—cultural characteristics of GD1

\section{Pathogenicity and Symptomatology}

Leaves inoculated with GD1 mycelium showed similar symptoms to naturally occurring leaf blight after two days of moisturizing at room temperature, while leaves inoculated with PDA medium showed no symptoms. The pathogens were re-isolated from the inoculated seedlings and compared with their original inoculated cultures. The re-isolated pathogens completely resembled the original inoculated fungi in their morphological, cultural and pathogenic characteristics, satisfying Koch's postulates. Pathogen inoculated plants developed initial symptoms as spotty brown discolouration of leaves. The spots were initially reddish-brown, with a diameter of $4.2-15.7 \mathrm{~mm}$. Subsequently, the lesion expanded and gradually turned to dark brown or black. (Figure 2A/2B.) 

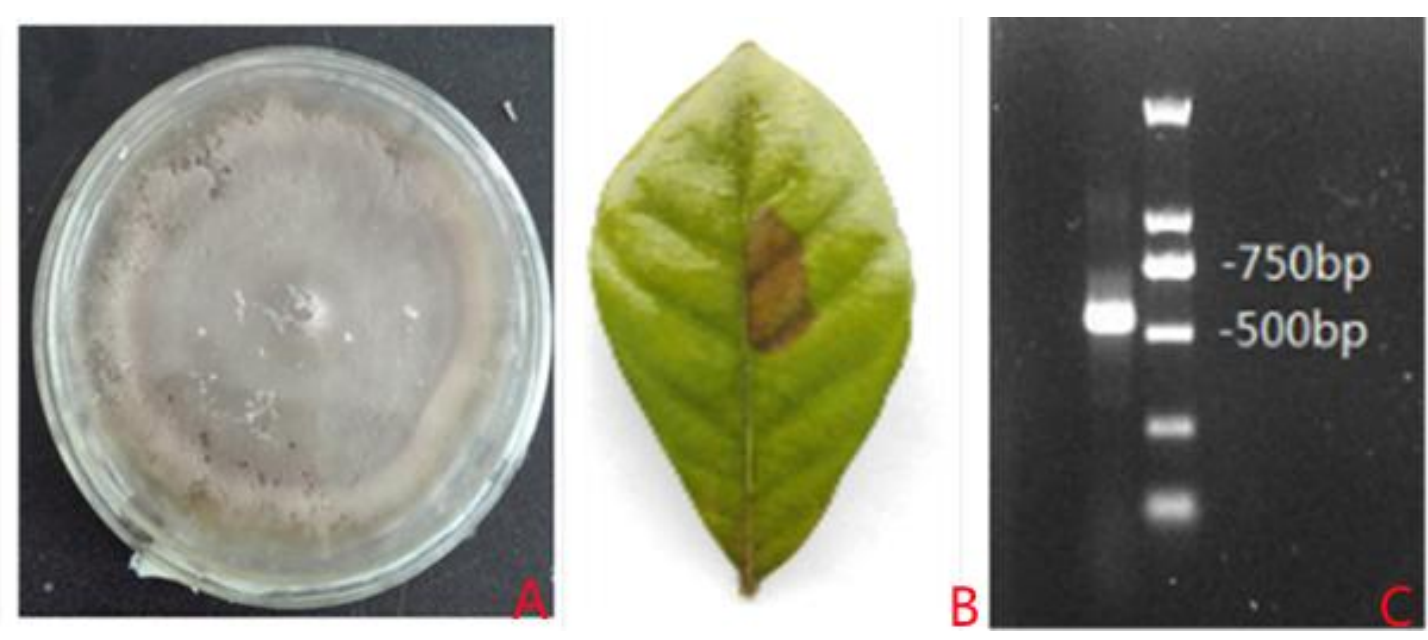

Fig2. Pathogenicity test of isolated GD1 on Gardenia leaf, and PCR product amplified from ITS Region in GD1.

\section{Molecular Characterization and phylogeny}

Pathogen template DNA and universal primers were used for rDNA-ITS sequence amplification of pathogen GD1, and a single band between 500-750bp was obtained, as shown in Figure 2C. After sequencing the PCR product and analyzing it with BLAST, our sequence showed 96\%-100\% sequence homology with GenBank sequences. GD1 Sequence was submitted to NCBI GenBank, and an accession number was obtained (OK041346). Phylogenetic analysis revealed that our isolates clustered along with other submitted Leaf blight isolates from GenBank. The sequences of GD1 formed the same cluster with Alternaria sp. (Fig. 3). Based on morphological and phylogenetic analysis, the pathogen GD1 was identified as Alternaria alternata (Fr.) Keissler. 


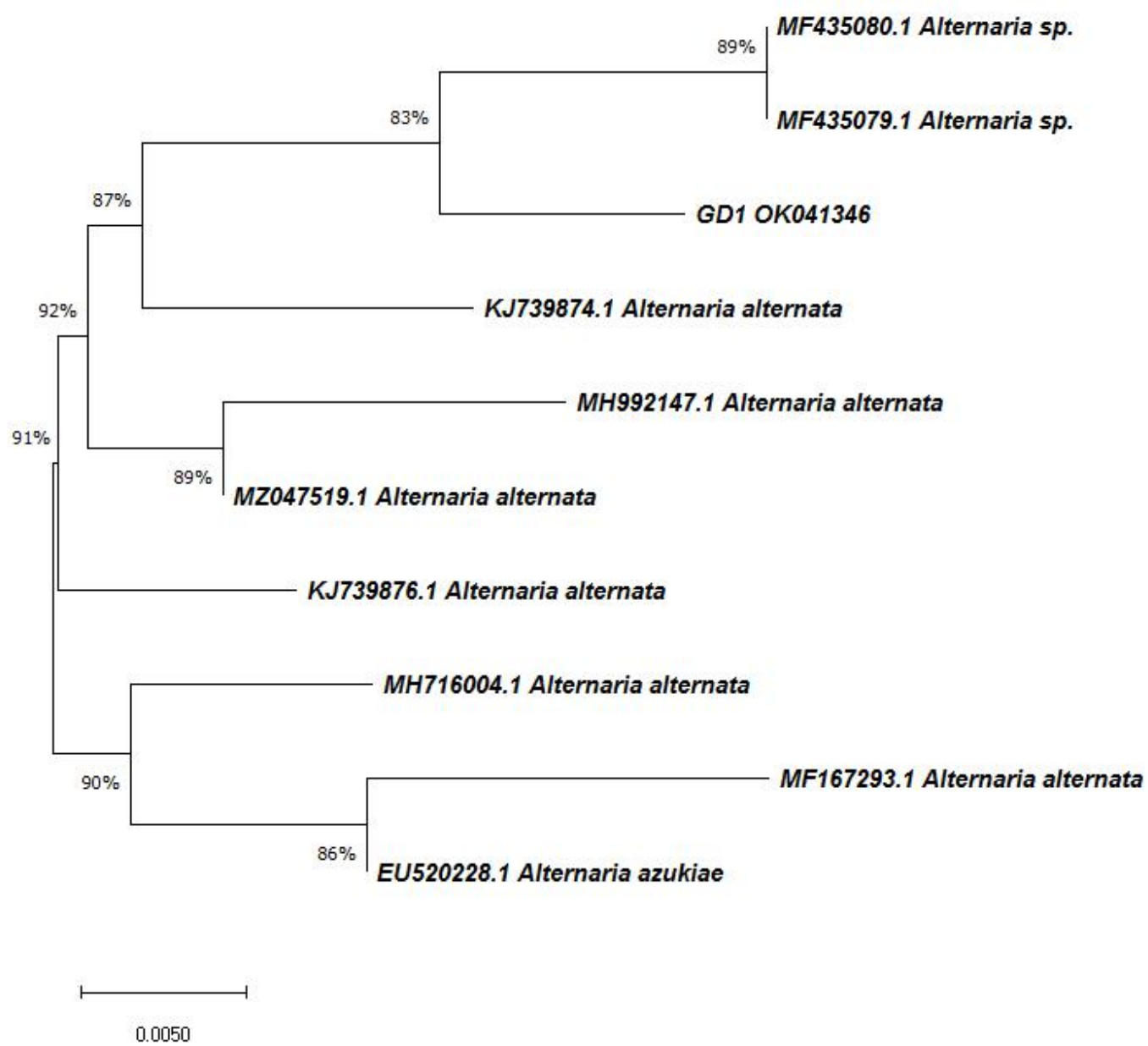

Fig3. Dendrogram generated by ITS sequence data predicting similarity

\section{In vitro fungicide testing}

Laboratory virulence tests of 15 tested fungicides against Alternaria alternata. showed that the inhibition effects of different fungicides were significantly different, as shown in Table 2 . The best antimicrobial agents were Hexaconazole with EC50 of $14.45 \mathrm{ppm}$, Chlorothalonil and Thiophanate-Methyl with $E_{50}$ of $40.92 \mathrm{ppm}, 67.92 \mathrm{ppm}$. Streptomycin(8912.51ppm), oxytetracycline(426.58ppm), Gentamycin sulfate(468.81ppm) and oligosaccharide(1196.74ppm) showed the worst 
antibacterial effect, which was not suitable for the control of a large area of disease. In this experiment, all the other tested agents had different inhibitory effects on the growth of Alternaria alternata(Table 2).

Table 2 The toxicity compar i son of $15 \mathrm{kinds}$ of fung icides to Alternaria alternata.

\begin{tabular}{|c|c|c|c|}
\hline ACTIVE INGREDIENT & $\begin{array}{c}\text { Concentration } \\
\quad(\mathrm{ppm})\end{array}$ & GR (\%) & $\mathrm{EC}_{50}(\mathrm{ppm})$ \\
\hline \multirow{5}{*}{ Thiram } & 10 & 1.03 & \multirow{5}{*}{67.92} \\
\hline & 30 & 15.94 & \\
\hline & 50 & 34.96 & \\
\hline & 70 & 49.61 & \\
\hline & 100 & 69.73 & \\
\hline \multirow{5}{*}{ Thiophanate-Methyl } & 20 & 25.08 & \multirow{5}{*}{47.53} \\
\hline & 40 & 52.77 & \\
\hline & 80 & 65.23 & \\
\hline & 120 & 71.48 & \\
\hline & 200 & 76.67 & \\
\hline \multirow{5}{*}{ Chlorothalonil } & 1 & 9.87 & \multirow{5}{*}{40.92} \\
\hline & 10 & 32.46 & \\
\hline & 50 & 48.34 & \\
\hline & 100 & 61.55 & \\
\hline & 150 & 70.69 & \\
\hline \multirow{5}{*}{ Dithane $z^{-78}$} & 10 & 6.80 & \multirow{5}{*}{73.52} \\
\hline & 100 & 38.88 & \\
\hline & 300 & 90.73 & \\
\hline & 400 & 94.85 & \\
\hline & 500 & 94.90 & \\
\hline \multirow{5}{*}{ Thiophanate-Methyl } & 100 & 0.29 & \multirow{5}{*}{714.49} \\
\hline & 300 & 18.98 & \\
\hline & 500 & 37.75 & \\
\hline & 700 & 49.43 & \\
\hline & 1000 & 57.84 & \\
\hline \multirow{5}{*}{$\begin{array}{l}\text { Moroxydine hydrochloride } \\
\text { 0ctreotide acetate }\end{array}$} & 50 & 11.31 & \multirow{5}{*}{311.17} \\
\hline & 100 & 21.84 & \\
\hline & 150 & 28.35 & \\
\hline & 200 & 38.93 & \\
\hline & 250 & 45.79 & \\
\hline
\end{tabular}




\begin{tabular}{|c|c|c|c|}
\hline \multirow{5}{*}{ carbendazim } & 100 & 5.29 & \multirow{5}{*}{481.95} \\
\hline & 300 & 29.48 & \\
\hline & 500 & 47.74 & \\
\hline & 700 & 64.35 & \\
\hline & 1000 & 80.94 & \\
\hline \multirow{5}{*}{ Tricyclazole } & 50 & 19.44 & \multirow{6}{*}{151.36} \\
\hline & 100 & 28.79 & \\
\hline & 150 & 40.09 & \\
\hline & 200 & 57.83 & \\
\hline & 250 & 78.52 & \\
\hline \multirow{5}{*}{$\begin{array}{c}\text { Carbendazim } \\
\text { Pentachloronitrobenzene }\end{array}$} & 100 & 0.93 & \\
\hline & 300 & 23.48 & \multirow{4}{*}{554.63} \\
\hline & 500 & 40.29 & \\
\hline & 700 & 61.84 & \\
\hline & 1000 & 79.75 & \\
\hline \multirow{5}{*}{ Hexaconazole } & 1 & 18.09 & \multirow{7}{*}{14.45} \\
\hline & 10 & 30.85 & \\
\hline & 30 & 56.38 & \\
\hline & 50 & 75.89 & \\
\hline & 70 & 77.48 & \\
\hline \multirow{5}{*}{ Oxytetracycline } & 10 & 0.35 & \\
\hline & 100 & 8.69 & \\
\hline & 500 & 42.02 & \multirow[t]{5}{*}{426.58} \\
\hline & 1000 & 83.87 & \\
\hline & 1500 & 84.57 & \\
\hline \multirow{5}{*}{ Streptomycin sulfate } & 1 & 4.64 & \\
\hline & 10 & 31.25 & \\
\hline & 100 & 49.82 & \multirow[t]{5}{*}{216.82} \\
\hline & 1000 & 52.86 & \\
\hline & 1500 & 54.46 & \\
\hline \multirow{5}{*}{ Gentamycin sulfate } & 100 & 8.37 & \\
\hline & 200 & 12.39 & \\
\hline & 500 & 38.43 & \multirow[t]{5}{*}{468.81} \\
\hline & 1000 & 59.58 & \\
\hline & 1500 & 98.29 & \\
\hline \multirow{5}{*}{ 01igosaccharins } & 200 & 15.96 & \\
\hline & 500 & 27.30 & \\
\hline & 1000 & 39.46 & \multirow[t]{3}{*}{1196.74} \\
\hline & 1500 & 52.94 & \\
\hline & 2000 & 69.33 & \\
\hline
\end{tabular}




$\begin{array}{cccc} & 200 & 1.43 & \\ \text { Streptomycin } & 500 & 5.24 & \\ & 1000 & 9.67 & 8912.51 \\ 1500 & 15.55 & \\ 2000 & 19.81 & \end{array}$

\section{Discussion}

Gardenia fruits are rich in natural pigments and geniposide, usually used as medicinal materials and natural dyes. And gardenia flowers smell fragrant, can be used as a landscaping plant. Alternaria alternata has been reported to cause leaf spot on Rumex dentatus in Pakistan (Siddiqui et al. 2009) and leaf blight of tomato reported from parts of Pakistan( Akhtar et al. 2010) and leaf spot on Yucca gloriosa in China. But Alternaria alternata has not been yet reported to cause gardenia leaf blight in Jiangxi province.

At present, the main measures of plant disease control still rely on pharmaceutical control. In the process of pesticide use, the effects of pesticide economy, safety and efficiency should be considered comprehensively to maximize the effectiveness of pesticides and minimize adverse factors. Comparing the bacteriostatic effects of 5 biological agents and 10 chemical agents on pathogenic bacteria, it was found that the control effect of biological agents was generally lower than that of chemical agents. The $\mathrm{EC}_{50}$ of streptomycin, oxytetracycline and oligosaccharide were all above 400ppm, which were not suitable for 
the control of large area diseases. The main characteristics of biopesticides are environmental protection, low toxicity and low pesticide residue rate. Chemical pesticides have better effects but are not conducive to environmental protection, and the pesticide residue rate is high. Therefore, multiple aspects need to be considered comprehensively in the choice of pesticide application. Plant growth promoting rhizobacteria is an effective and eco-sustainable solution to protect crops against phytopathogens. Bacillus safensis STJP (NAIMCC-B-02323) from the rhizospheric soil of Stevia rebaudiana showed strong biocontrol activity against phytopathogen, Alternaria alternata(Prakash et al. 2021). As a biopesticide, biological control bacteria have the advantages of environmental protection and sustainability, and may become the next hot spot of plant protection research.

\section{References}

Zhang WW, Zhang FL, Hu QC, Xiao XL, Ou LB, Chen Y, Luo SQ, Cheng YH, Jiang YX, Ma $X$, Zhao YL (2021) The merging possibility of the use of geniposide in the treatment of cerebral diseases: a review. Chin Med 16(1), 86

Wu J, Zhang JT, Yu X, Shu Y, Zhang SY, Zhang YL (2021) Gardenia jasminoidesExtraction optimization by using response surface methodology and purification of yellow pigment from var. Makikno. Food Sci Nutr 9(2), 822-832

Mehl KM, Mikel MA, Bradley CA (2021) Clavibacter nebraskensisEvaluation of Corn Germplasm Accessions for Resistance to , Causal Agent of Goss's Bacterial Wilt and Leaf Blight. Plant Dis 105(1), 156-163

Gálvez L, Gil-Serna J, García M, Iglesias C, Palmero D (2016) Stemphylium Leaf Blight of Garlic in Spain: Taxonomy and Fungicide Response. Plant Pathol J 32(5), 388-395 
Siddiqui I, Bajwa R, Javaid A (2009) First report of alternaria alternata causing leaf spot on rumex dentatus in pakistan. Plant Dis 93(4), 43

Akhtar KP, Saleem MY, Asghar M, Haq MA (2010) New report of alternaria alternata causing leaf blight of tomato in pakistan. Plant Pathology, 53.

Prakash J, Arora NK (2021) Novel metabolites from Bacillus safensis and their antifungal property against Alternaria alternata. Antonie Van Leeuwenhoek 114(8), 1245-1258

\section{Credit authorship contribution statement}

Anna Zhao \& Guangming Luo Conceptualization, Methodology, Investigation, Validation, Supervision, Funding acquisition, Writing original draft. Yuhong Gong, Yangjin Luo, and Dandan Song: Data curation, Formal analysis, Visualization. Hongdong Xia: Methodology, Investigation, Writing-review \& editing.

Funding This study was supported by China's National Key Research and Development Program (2017YFC1700902), National Public Welfare Research Program of China (201707002).

\section{Declarations}

Ethical approval This article does not contain any studies with human participants or animals performed by any of the authors.

Declaration of competing interest The authors declare that they have no conflict of interest.

Declaration of Plant samples collection Our plant samples were collected from gardenia planting base. The samples are not wild plants and have been approved by the site owner. We comply with the IUCN 
Policy Statement On Research Involving Species at Risk of Extinction and the Convention on the Ttade in Endangered Species of Wild Fauna and Flora. We strict compliance with relevant institutions, national and international guidelines and legislation. 


\section{Supplementary Files}

This is a list of supplementary files associated with this preprint. Click to download.

- table.docx 